\title{
A comparison of postharvest quality of breadfruit (Artocarpus altilis) after disinfestation with hot air or hot water treatments
}

\author{
Seeseei Molimau-Samasoni ${ }^{1,2, *}$, Veronica Vaaiva ${ }^{1}$, Semi Seruvakula ${ }^{1}$, Angelika Tugaga ${ }^{1}$, \\ Guinevere Ortiz ${ }^{3,4}$, Stephen Wallace ${ }^{3,4}$, Mark Seelye ${ }^{3,4}$, Barbara C. Waddell ${ }^{3,4}$, Samuel D.J. \\ Brown $^{3,4}$, Lisa E. Jamieson ${ }^{3,4}$ and Allan Woolf ${ }^{3,4}$ \\ ${ }^{1}$ Scientific Research Organization of Samoa, PO BOX 6597, Nafanua, Apia, Samoa \\ ${ }^{2}$ The University of the Sunshine Coast, Locked Bag 4, Maroochydore Queensland 4558, \\ Australia \\ ${ }^{3}$ The New Zealand Institute for Plant and Food Research Limited, Private Bag 92169, Auckland, \\ 1142, New Zealand \\ ${ }^{4}$ Better Border Biosecurity (http://b3nz.org/) \\ ${ }^{*}$ Corresponding author: seeseei.molimau-samasoni@srosmanagement.org.ws
}

\begin{abstract}
Breadfruit from Samoa potentially host the Pacific fruit fly (Bactrocera xanthodes) and so their export to New Zealand requires a disinfestation treatment. Heat treatments by air (HAT) or water (HWT) are common fruit-fly disinfestation treatments for tropical crops. Two breadfruit cultivars - Puou and Ma'afala - were subjected to three heat treatments, HAT- 1 (minimum $47.2^{\circ} \mathrm{C}$ for $20 \mathrm{~min}$ at core), HAT-2 $\left(49.0^{\circ} \mathrm{C}\right.$ for $100 \mathrm{~min}$ at core) and HWT $\left(47.2^{\circ} \mathrm{C}\right.$ for $20 \mathrm{~min}$ at core), and an untreated control was also included. Fruit were stored for one week at $15^{\circ} \mathrm{C}$ followed by three days at $25^{\circ} \mathrm{C}$. Disorders observed were heat damage to the skin (blackening) and increased decay on the body and stem-end. Heat damage was at an acceptably low level following HAT-1 but was unacceptable following HAT-2 or HWT. Initial results suggest that a HAT can be tolerated, but the effect of ramp rate and the potential of using a two-step HWT system should be examined.
\end{abstract}

Keywords heat treatments, fruit fly, Bactrocera xanthodes, Pacific fruit fly

\section{INTRODUCTION}

Breadfruit (Artocarpus altilis), is a starchy fruit native to the Pacific Islands (Worrell et al. 2002). It is locally known as 'Ulu' in Samoa (Christophersen, 1935) and the most preferred cultivars are Puou and Ma'afala. Puou is large and round, with a light texture whereas Ma'afala is smaller and denser than Puou. There is currently interest in developing the export potential of breadfruit, especially from countries such as Samoa and Fiji into high-value markets like New Zealand and Australia where there are large expatriate Pacific Island populations. However, breadfruit is a known host of the Pacific fruit fly (Bactocera xanthodes) and this pest does not currently occur in New Zealand. Therefore, breadfruit (and other fruit-fly host commodities) imported into New Zealand must undergo a disinfestation treatment prior to export.

This treatment involves high temperature forced air (HTFA) which involves slowly heating the fruit core until the temperature required to kill fruit fly eggs and larvae is reached $\left(47.2^{\circ} \mathrm{C}\right.$ for 20 mins), followed by rapid hydrocooling (Waddell et al. 1997). The quarantine HTFA treatment is based on a treatment schedule developed in the Cook Islands for papaya (Carica papaya), which was subsequently applied as a generic fruit fly 
treatment for a range of crops, in a number of Pacific Island countries, including Samoa. The fruit fly species of biosecurity concern in Samoa are less heat tolerant than the species (Bactocera melanotus) that is found in the Cook Islands for which the treatment was developed (Waddell et al. 1997; Tunupopo et al. 2019). There are advantages in adopting a generic treatment but the current treatment is harsher than needed in this instance, and also increases the likelihood of postharvest rots and other fruit quality disorders in breadfruit, which is a relatively delicate fruit. A similar situation may exist in Fiji, where again the Cook Islands generic treatment is currently applied to breadfruit and other export commodities.

There has been anecdotal evidence that the HTFA treatment $\left(47.2^{\circ} \mathrm{C}\right.$ core temperature for $20 \mathrm{~min}$ ) causes heat damage to breadfruit (Finau et al., unpublished data). One possible reason for heat damage during hot air treatments is the temperature differential that occurs across the individual fruit as they are heated during treatment. Fruit are loosely stacked into each of four bins ( $1.23 \times 1.23 \times 1.0 \mathrm{~m}$; L x W x H) to a depth of $0.8 \mathrm{~m}$. Air is heated by a heat exchanger and then forced by a fan through the spaces between the fruit, entering the bottom of each bin and exiting the top. Consequently, fruit in the lower part of the bin, and smaller fruit, will be held at the treatment temperature for a longer period than the top layer of fruit. Phytosanitary approval is granted when the heating profile of the largest fruit in the coldest position (located at the top of the treatment stack) shows that core temperature had been maintained at a temperature of at least $47.2^{\circ} \mathrm{C}$ for 20 mins (Waddell et al. 1997).

Similar treatments involving hot water (HWT) are used for fruit fly disinfestation in a range of crops including mango (Mangifera indica) (Sharp et al. 1989a; Sharp et al. 1989b; Nascimento et al. 1992; Ndlela et al. 2017).

This work aimed to examine the effect of HTFA and HWT on the quality of breadfruit and discusses the potential of reducing the severity of the HTFA treatment to suit the tolerance of fruit fly species present in Samoa and Fiji, while maintaining acceptable quality of breadfruit.

\section{MATERIALS AND METHODS \\ Breadfruit collection and preparation for treatment}

Mature breadfruit (Ma'afala and Puou) were harvested from household trees in Upolu, Samoa on 3 and 4 April 2019, respectively. Fruit stalks were immediately covered with paper (to protect against latex staining) and carefully placed in collapsible harvesting crates to prevent damage. Fruit were then transported to the Scientific Research Organization of Samoa (SROS) Postharvest Laboratory where the stalks were trimmed to $3 \mathrm{~cm}$, and latex exudate was allowed to drain. Fruit were then numbered, weighed, sorted into replicate treatment groups and stored at $20^{\circ} \mathrm{C}$ overnight. Puou fruit had an average weight of $1077 \mathrm{~g}$, while Ma'afala fruit had an average weight of $693 \mathrm{~g}$. The weight of fruit used as the "temperature probe fruit" was kept within $\pm 20 \mathrm{~g}$ of the overall fruit average. The probed fruit (one per replicate) were placed in the centre of the heat chamber or water bath and not used for fruit assessments.

\section{Treatment summary}

Four treatments were carried out: Control (held at $20^{\circ} \mathrm{C}$ ); hot air treatments at $47.2^{\circ} \mathrm{C}$ for 20 mins at core (HAT-1) and $49.0^{\circ} \mathrm{C}$ for $100 \mathrm{~min}$ at core (HAT-2); and a hot water treatment at $48.5^{\circ} \mathrm{C}$ with a core temperature of $47.2^{\circ} \mathrm{C}$ for 20 mins (HWT). Heat treated fruit were hydrocooled. External quality assessment was carried out 1 day after heat treatment, and external and destructive assessments were carried out at the end of 1 week at $15^{\circ} \mathrm{C}$ (simulated airfreight), and after 3 days at $25^{\circ} \mathrm{C}$ (simulated shelf life).

\section{Hot air treatments}

There were three replicates for each cultivar comprising 15 fruits each (total of 90 fruits excluding 6 probe fruits). Fruit were exposed to one of two hot air treatments: a fruit core temperature of $47.2^{\circ} \mathrm{C}$ for 20 mins (HAT-1), or core temperature of $49.0^{\circ} \mathrm{C}$ for 100 mins (HAT-2). Details of temperature settings and 
Table 1: Summary of detailed heating temperatures and times used for heat treatments of two breadfruit cultivars

\begin{tabular}{llll}
\hline Parameter & HAT-1 & HAT-2 & HWT \\
\hline Core target temperature (Maafala \& Puou); ${ }^{\circ} \mathrm{C}$ & 47.2 & 49.0 & 47.2 \\
Time @ core target temperature (Maafala \& Puou); min & 20 & 100 & 20 \\
Maximum air/water temperature (Maafala \& Puou); ${ }^{\circ} \mathrm{C}$ & 49.7 & 51.5 & 48.5 \\
Heating ramp duration - Maafala; h & 4 & 2 & $1-2$ \\
Heating ramp duration - Puou; h & 3 & 2 & $1-2$ \\
\hline
\end{tabular}

ramp (heating) times are shown in Table 1. The combination of a higher temperature and longer time was selected to represent conditions that a smaller fruit in the hot spot of an HTFA unit might experience. This rationale was described for HAT of dragon fruit (Hylocereus undatus; Hoa et al. 2006).

Treatments were conducted within six hot-air chambers (147 L each) (where each HAT used 3 chambers as replicates, and each chamber had 15 fruits plus one probe fruit) each equipped with a heating element, PT100 temperature sensors and a recirculating fan to ensure even heating of each chamber. This chamber design is an upgraded version of that described in Woolf et al. (1995).

A bespoke LabVIEW application (National Instruments, TX, USA) utilising a closed loop proportional-integral-derivative (PID) controller connected to a Data Actuation Card (Intech, London) allowed user-defined temperature profiles to be loaded in order to control precisely the air temperatures within individual chambers, by controlling the heating element. The LabVIEW application also logged and displayed real-time temperature profiles (air, surface, and core) and relative humidity of each chamber. The heating times were different for the two cultivars because Puou fruit are generally 300-400 g larger than Maafala. The appropriate heating times and air/fruit temperature differentials had been determined in previous trials (data not shown).

Ma'afala fruit exposed to HAT-1 were loaded into chambers $1-3$ (i.e. three replicate simultaneous HAT-1s), with an air heating rate of $4 \mathrm{~h}$ to target temperature, while Ma'afala fruit exposed to HAT-2 were loaded into chambers 4-6 with a heating rate of $2 \mathrm{~h}$ to target temperature.

The following day, Puou fruit exposed to HAT- 1 were heat treated in chambers $1-3$ with a heating rate of $3 \mathrm{~h}$ to target temperature, while Puou fruit exposed to HAT-2 were loaded into chambers 4-6 with a heating rate of $2 \mathrm{~h}$ to target temperature.

An initial holding temperature of $30^{\circ} \mathrm{C}$ was applied for 30 mins then the temperature was increased to $49.7^{\circ} \mathrm{C}$ for HAT- 1 or $51.2^{\circ} \mathrm{C}$ for HAT2, which allowed for a $2.5^{\circ} \mathrm{C}$ air-fruit differential. Fruit were removed from the chamber 20 mins after the core of the probe fruit reached $47.2^{\circ} \mathrm{C}$ for HAT-1, and 100 mins after the core of the probe fruit reached $49.0^{\circ} \mathrm{C}$ for HAT-2 (Table 1). Typical air and core temperatures are shown in Fig. 1A. At the completion of treatment times, fruit were hydrocooled then stored at $20^{\circ} \mathrm{C}$ overnight. Relative humidity was not controlled, but was measured using a wet-dry bulb system and found to be between $\approx 70$ and $80 \%$ for the majority of the treatment period.

\section{Hot-water treatment}

Three replicates of 15 fruit each for the cultivars Puou and Ma'afala were treated in hot water by submersion in a $90-\mathrm{L}$ water bath equipped with $150-\mathrm{W}$ heater and recirculating pump (Woolf \& Lay-Yee 1997) to hold the water temperature at $48.5^{\circ} \mathrm{C}$ (water-fruit differential from target of $1.3^{\circ} \mathrm{C}$ ). Fruit were submerged in hot water until the core temperature had been maintained at 

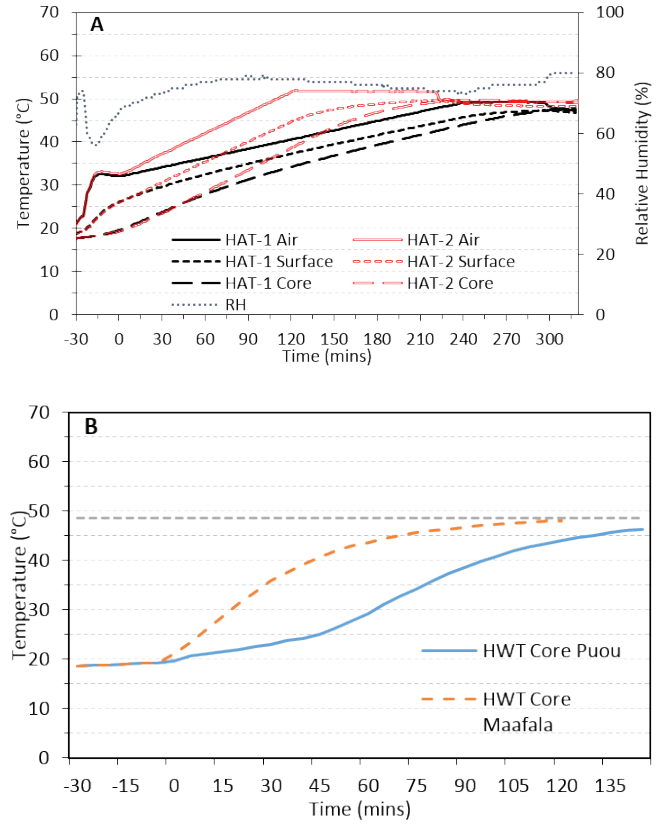

Figure 1 Temperatures for hot air (HAT) and hot water treatments (HWT). (A): Air, core and surface temperatures are shown for Ma'afala HAT-1 (black) and HAT-2 (red) and relative humidity (RH) (grey) for Ma'afala HAT-1. (B): The core temperature of Puou (blue) and Ma'afala (orange) for HWT is shown and, although not logged, water temperature was $48.5^{\circ} \mathrm{C} \pm 0.2^{\circ} \mathrm{C}$ (grey dotted line).

$47.2^{\circ} \mathrm{C}$ (or more) for $20 \mathrm{mins}$ (Table 1 ).

After heat treatment, fruit were hydrocooled then kept at $20^{\circ} \mathrm{C}$ overnight. Typical core temperatures are shown in Fig. 1B.

\section{Temperature measurement}

Temperatures were measured using Log Tag data loggers (TRED30-16R, Germany) and Ebro temperature probes (TFX410, Ingolstadt, Germany) for HWT work, and PT100 temperature probes for the HAT. All temperature measuring devices were checked against a reference temperature probe at $50^{\circ} \mathrm{C}$.

\section{Hydrocooling}

Heat-treated fruit were hydrocooled using showers of town-supply water (temperature $\approx$ $25^{\circ} \mathrm{C}$ ) running-to-waste over fruit till the core reached $35^{\circ} \mathrm{C}(1-2 \mathrm{~h})$.

\section{Fruit assessments}

Fruit were assessed for skin colour, firmness and weight on the day after heat treatment (2 days after harvest). With the exception of the control fruit, fruit were also assessed for heat damage. All fruit (Control, HAT-1, HAT-2 and HWT) were then placed in lined crates and stored at $15^{\circ} \mathrm{C}$, to simulate airfreight to market.

After one week at $15^{\circ} \mathrm{C}$, fruit were re-assessed for colour, firmness, weight, cool store injury and rot. Fruit that showed signs of rot or reached the maximum cool store injury rating were discarded. Remaining fruit were held for three days at $25^{\circ} \mathrm{C}$ (room temperature (RT), to simulate shelf life in crates without liners then re-assessed for colour, firmness, weight and rot.

External quality was rated by eye and touch according to the following system:

- Heat injury*: Browning and blackening on fruit surface localised to polygonal indentations of breadfruit peel observed only after heat treatment. (Figs. 2A \& 2B).

- Cool store injury*: Generalised browning not observed before and after heat treatment, and not resulting from latex stains (Fig. 2C).

- Rot ${ }^{*}$ : Soft, well-defined brown spots visible on the surface.

- Fruit firmness: Determined by hand with the following scale: 1 = hard; 2 = moderately hard; 3 = starting to soften; 4 = medium soft; 5 = very soft and spongy.

- Skin colour: Rating of 1 = deep green; 2 = light green; $3=25-50 \%$ yellow; $4=>50 \%$ yellow and slight browning; $5=$ predominantly brown.

- Levels of 4 and above are considered unacceptable quality.

*The following rating scale was used for heat damage, cool store injury and rots: $1=$ none; 2 $=0.5-5 \%$ of surface; $3=>5-15 \% ; 4=>15-50 \%$; $5=>50 \%$. 

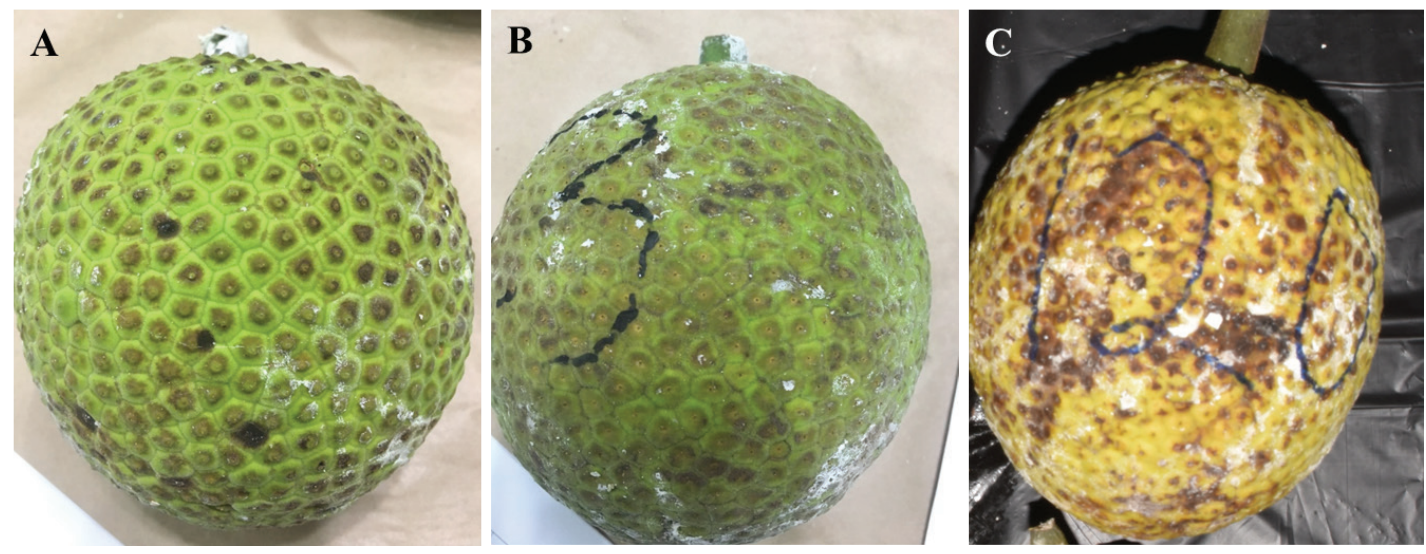

Figure 2 Examples of fruit quality disorders measured after heat treatment and cold storage. Heat injury in (A) Ma'afala and (B) Puou. (C) Cool store injury.

\section{Statistical analyses}

The significance of difference between treatment groups per day of assessment per fruit quality assessed and Least Significant Difference was calculated to $\mathrm{P}<0.05$ using one-way analyses of variance (ANOVA) in Microsoft Excel.

\section{RESULTS}

Ma'afala untreated fruit (Control) showed minimal rots, but had softened and displayed an unacceptable amount of skin browning after 1 week of storage at $15^{\circ} \mathrm{C}$ (Fig. 3). These symptoms worsened after 3 days at RT. In contrast, HAT1 fruit retained an acceptable degree of firmness with no rots after cold storage at $15^{\circ} \mathrm{C}$ for a week, and the trend was maintained after fruit were kept for a further three days at RT. Ma'afala fruit quality was significantly lower following HAT-2 or HWT than following HAT-1. Between 5\% and $15 \%$ of the surface was affected by heat on fruit treated with either HAT-2 or HWT. However, all treatments and the control showed similar rates of cool store injury.

Puou untreated fruit (Control) had minimal rot incidence after 1 week in $15^{\circ} \mathrm{C}$, but had softened and showed cool store injury (Fig. 4). After 3 days at RT, these symptoms worsened although the incidence of rot still remained low. After heat treatments, comparable heat injury was observed from all three heat treatments, but it was not significantly different to the lack of heat injury observed from control fruit (Fig. 4). After cool store, only HAT-2 and HWT fruit had fruit quality scores greater than 3 in cool store injury and colour. After fruit were kept at RT for 3 days, all fruit had quality scores greater than 3 , with the exception of firmness and rot development in HAT-1 fruit, and rot development only in control fruit. Notably, fruit quality was comparable between the control and HAT-1 except in fruit firmness, while fruit quality was similar between HAT-2 and HWT except also for firmness.

\section{DISCUSSION}

Previous observations of the incidence of rots and poor fruit quality following treatment at a commercial HTFA facility (Finau et al. unpublished data) prompted this investigation into alternative heat treatments and their effect on breadfruit quality. This research showed that there was a higher incidence of rot from fruit treated by the more severe HAT-2 treatment conditions than the standard HAT-1 treatment conditions, suggesting that fruit at the bottom of the treatment stack and smaller fruit are more prone to higher temperature treatments for longer durations and are likely to show higher rot incidence. This also suggests that either lower fruit temperatures, shorter treatment duration and/or reduced temperature variation (for 


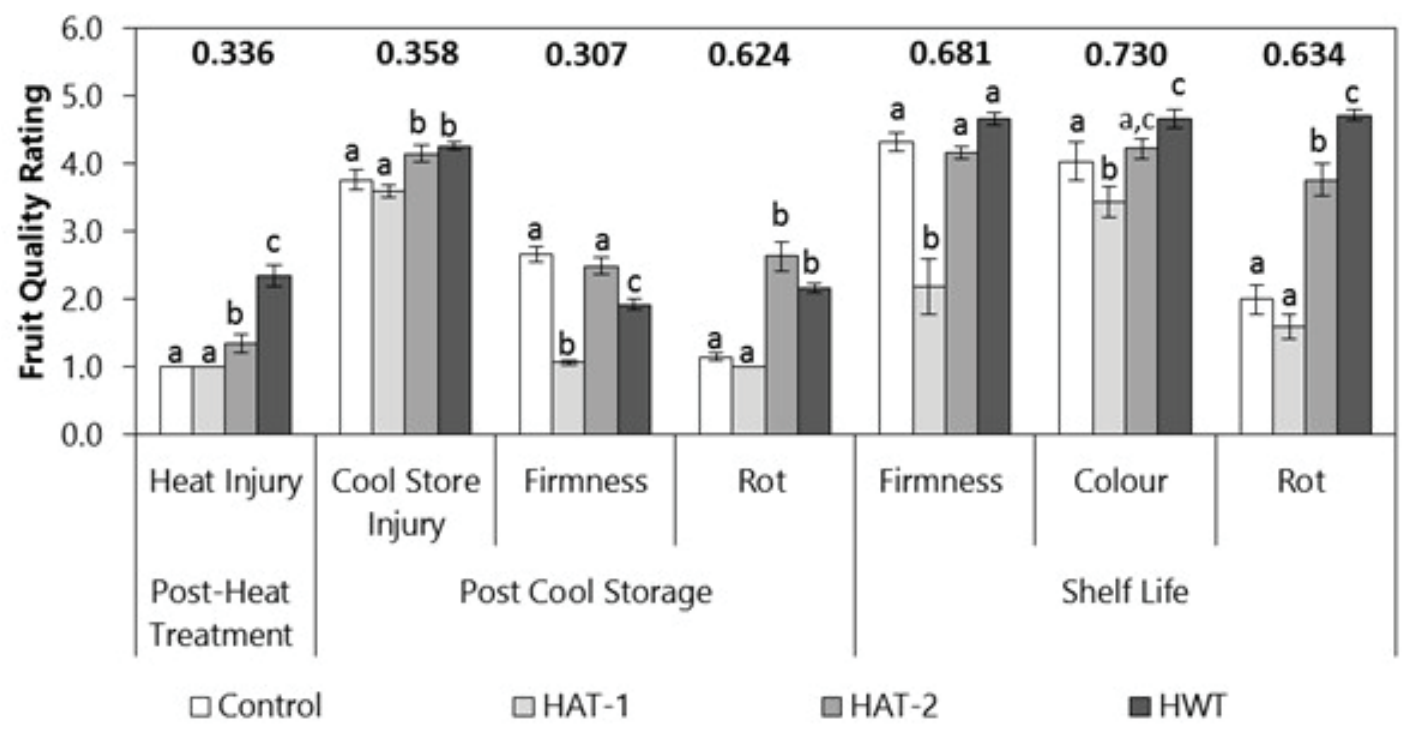

Figure 3 Fruit quality of Ma'afala fruit after heat treatments. Fruit were assessed after heat treatment (post heat treatment), after one-week storage at $15^{\circ} \mathrm{C}$ (post cool storage), and after three days at $25^{\circ} \mathrm{C}$ (shelf life). Only fruit quality parameters with statistically significant differences between treatments are shown. HAT- 1 denotes hot air treatment of $47.2^{\circ} \mathrm{C}$ for 20 mins at the fruit core, HAT-2 is hot air treatment at $49.0^{\circ} \mathrm{C}$ for 100 mins at the fruit core and HWT is hot water treatment of core at $47.2^{\circ} \mathrm{C}$ for 20 mins. Different letters above bars indicate statistical difference of specific fruit quality measure between treatments as calculated by LSD (bold numbers above). Vertical bars represent \pm standard error (SE).

example by using alternating air-flow direction) would be beneficial in reducing rots in breadfruit induced by quarantine heat treatment.

The maximum temperature of the HWT was the same as HAT-1 and lower than HAT-2 but reduction in quality of the fruit treated by HWT was comparable to that of fruit treated by HAT-2. HWT resulted in greater heat damage than HAT1 , and is likely due to the more rapid transfer of heat to the skin by water than by air. Therefore, the potential of using a two-step HWT system will be examined in the future.

Breadfruit is the preferred host of $B$. xanthodes (Tora Vueti et al. 1997b). This species has a relatively low heat tolerance compared to $B$. melanotus, for which the HTFA treatment was developed. HTFA treatments of $B$. xanthodesinfested breadfruit showed complete mortality at temperatures higher than $43^{\circ} \mathrm{C}$ with no hold time (Tunupopo et al. 2019). This is consistent with research on $B$. xanthodes in other Pacific Island Countries (Foliaki \& Armstrong 1997; Tora Vueti et al. 1997a). The other fruit fly species of economic importance in Samoa, $B$. $k i r k i$, can survive up to $46^{\circ} \mathrm{C}$ with no hold time in HTFA treated eggplants (Solanum melongena) (Tunupopo et al. 2019). Both these temperatures are lower than the target HTFA temperature of $47.2^{\circ} \mathrm{C}$, which was developed as a generic treatment for Pacific Islands fruit flies after it was shown that $24 \mathrm{~h}$ eggs of B. melanotus in the Cook Islands was the most heat tolerant species in the region (Waddell et al. 1997). Results from this study and Tunupopo et al. (2019) show the potential of lower HTFA quarantine treatments being developed for Samoan horticulture. 


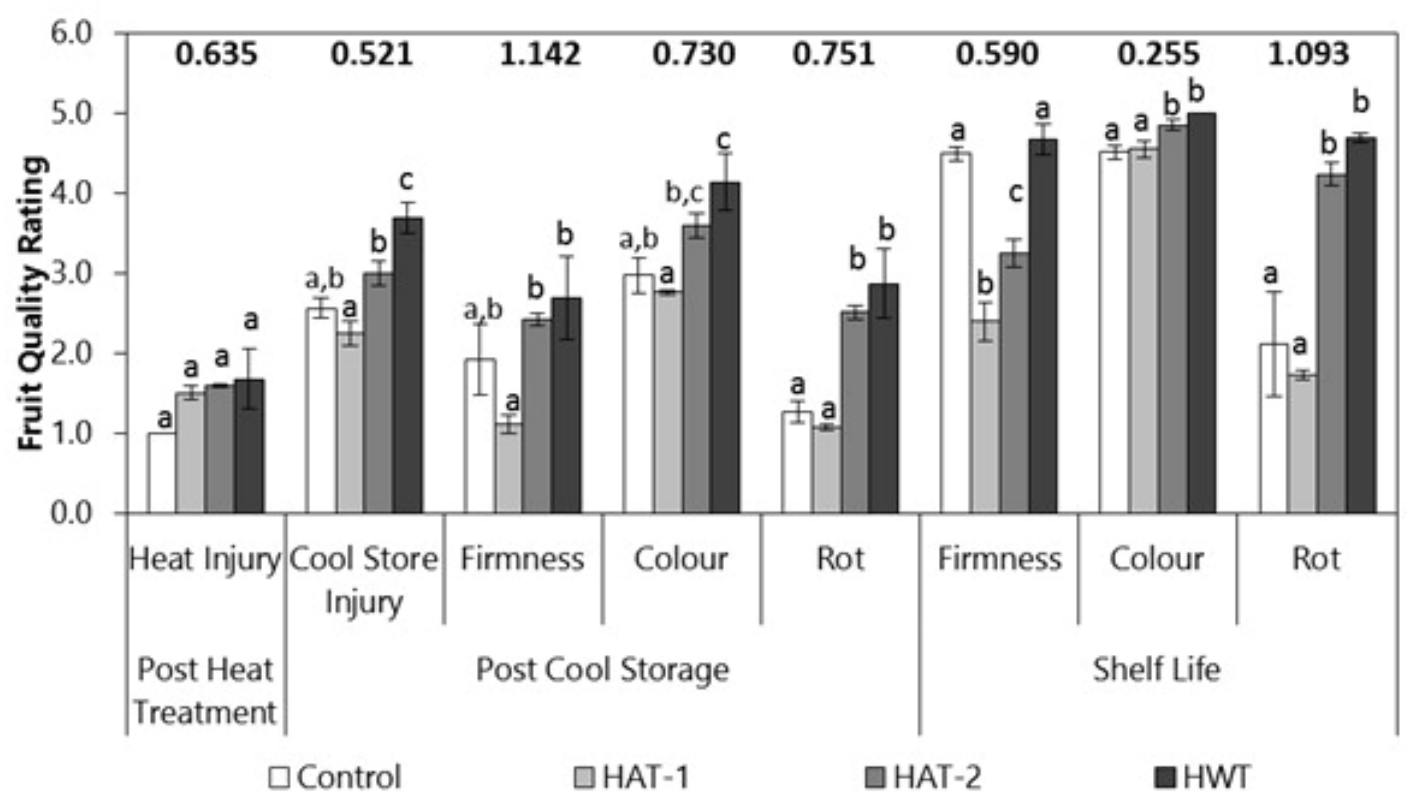

Figure 4 Fruit quality of Puou after heat treatments. Fruit were assessed after heat treatment (post heat treatment), after one week storage at $15^{\circ} \mathrm{C}$ (post cool storage), and after three days at $25^{\circ} \mathrm{C}$ (shelf life). HAT-1 denotes hot air treatment of $47.2^{\circ} \mathrm{C}$ for 20 mins at the fruit core, HAT-2 is hot air treatment at $49.0^{\circ} \mathrm{C}$ for 100 mins at the fruit core and HWT is hot water treatment of the fruit core at $47.2^{\circ} \mathrm{C}$ for 20 mins. Different letters above bars indicate statistical difference of specific fruit quality measured between treatments as calculated by LSD (bold numbers above). Vertical bars represent \pm standard error (SE).

\section{CONCLUSIONS}

While there are significant challenges to achieving a quality outturn of breadfruit, these results suggest that an appropriate heat treatment can be developed that can disinfest breadfruit of the target fruit fly species in Samoa.

\section{ACKNOWLEDGEMENTS}

We acknowledge the many scientists and colleagues who contributed to this work. We are particularly indebted to Emeritus Professor Ron B. Wills (University of Newcastle, NSW) for initiating this research study and Professor Steven Underhill (University of Queensland/University of the Sunshine Coast) for his support. We also want to acknowledge the technical assistance of Mulipola Autalavou Mila, Sosaiete Fa'atuiese and Tiperio Wendt (SROS). This research was funded by Plant and Food Research SSIF funding through the Better Border Biosecurity (B3) research collaboration and the ACIAR HORT 2014/077 Enhanced Fruit Production and Postharvest Handling Systems for Fiji, Samoa and Tonga Project.

\section{REFERENCES}

Christophersen E 1935. Flowering plants of Samoa. Bernice P. Bishop Museum Bulletin 128: 1-221.

Foliaki S, Armstrong JW 1997. Heat tolerances of immature stages of Bactrocera facialis and $B$. xanthodes (Diptera: Tephritidae). In: Allwood AJ, Drew RAI eds. Management of Fruit Flies in the Pacific. A regional symposium, Nadi, Fiji 28-31 October 1996. Australian Centre for International Agricultural Research, Canberra. Pp. 239-246.

Hoa TT, Clark CJ, Waddell BC, Woolf $\mathrm{AB}$ 
2006. Postharvest quality of dragon fruit (Hylocereus undatus) following disinfesting hot air treatments Postharvest Biology and Technology. 41; 62-69.

Nascimento AS, Malavasi A, Morgante JA, Duarte ALA 1992. Hot-water immersion treatment for mangoes infested with Anastrepha fraterculus, A. obliqua, and Ceratitis capitata (Diptera: Tephritidae) in Brazil. Journal of Economic Entomology 85: 456-460.

Ndlela S, Ekesi S, Ndegwa PN, Ongamo GO, Mohamed SA 2017. Post-harvest disinfestation of Bactrocera dorsalis (Hendel) (Diptera: Tephritidae) in mango using hot-water treatments. Journal of Applied Entomology 141: 848-859.

Sharp JL, Ouye MT, Ingle SJ, Hart WG 1989a. Hotwater quarantine treatment for mangoes from Mexico infested with Mexican fruit fly and West Indian fruit fly (Diptera: Tephritidae). Journal of Economic Entomology 82: 16571662.

Sharp JL, Ouye MT, Hart W, Ingle S, Hallman G, Gould W, Chew V 1989b. Immersion of Florida mangos in hot water as a quarantine treatment for Caribbean fruit fly (Diptera: Tephritidae). Journal of Economic Entomology 82: 186-188.

Tora Vueti E, Ralulu L, Leweniqila L, Balawakula A, Frampton CM 1997a. Heat tolerances of immature stages of Bactrocera passiflorae (Froggatt) and B. xanthodes (Broun) in Fiji. In: Allwood AJ, Drew RAI eds. Management of Fruit Flies in the Pacific. A regional symposium, Nadi, Fiji 28-31 October 1996. Australian Centre for International Agricultural Research, Canberra. Pp. 234238.

Tora Vueti E, Ralulu L, Walker GP, Allwood AJ, Leweniqila L, Balawakula A 1997b. Host availability-its impact on seasonal abundance of fruit flies. In: Allwood AJ, Drew RAI eds. Management of Fruit Flies in the Pacific. A regional symposium, Nadi, Fiji 28-31 October 1996. Australian Centre for International Agricultural Research, Canberra. Pp. 105-110.
Tunupopo F, Sa'ili F, Jamieson LE, Brown SDJ 2019. Development of heat treatments for Samoan fruit flies (Bactrocera spp., Diptera: Tephritidae). New Zealand Plant Protection 72: 59-66.

Waddell BC, Clare GK, Petry RJ, Maindonald JH, Purea M, Wigmore W, Joseph P, Fullerton RA, Batchelor TA, Lay-Yee M 1997. Quarantine heat treatment for Bactrocera melanotus (Coquillett) and B. xanthodes (Broun) (Diptera: Tephritidae) in Waimanalo papaya in the Cook Islands. In: Allwood AJ, Drew RAI eds. Management of Fruit Flies in the Pacific. A regional symposium, Nadi, Fiji 28-31 October 1996. Australian Centre for International Agricultural Research, Canberra. Pp. 251-255.

Woolf AB, Watkins CB, Bowen JH, Lay-Yee M, Maindonald JH, Ferguson IB 1995. Reducing external chilling injury in stored 'Hass' avocados with dry heat treatments. Journal of the American Society for Horticultural Science. 120, 1050-1056.

Woolf AB, Lay-Yee M 1997. Pretreatments at $38^{\circ} \mathrm{C}$ of 'Hass' avocado confer thermotolerance to $50^{\circ} \mathrm{C}$ hot-water treatments. HortScience. 32(4): 705-708.

Worrell DB, Carrington CMS, Huber, DJ 2002. The use of low temperature and coatings to maintain storage quality of breadfruit, Artocarpus altilis (Parks.) Fosb. Postharvest Biology and Technology 25, e33040 